\title{
Riedel's thyroiditis associated with hypothyroidism and hypoparathyroidism
}

\author{
F. Marín, R. Araujo, C. Páramo, T. Lucas and L. Salto \\ Servicio de Endocrinología, Clínica Puerta de Hierro, Universidad Autónoma, 28035 Madrid, Spain.
}

\begin{abstract}
Summary: Hypoparathyroidism secondary to Riedel's thyroiditis is rare, only 2 previous cases having been reported. We present the case of a 36 year old woman with Riedel's thyroiditis which developed into hypothyroidism and hypoparathyroidism.
\end{abstract}

\section{Introduction}

Riedel's thyroiditis is a rare disorder in which the normal thyroid parenchyma is replaced by a dense fibrous tissue which extends beyond the limits of the thyroid gland and invades adjacent structures in the neck. ${ }^{1}$ The incidence has been calculated to be $0.06 \%$ of a total of 56,700 thyroidectomies. ${ }^{2}$ We present the case of a female patient with Riedel's thyroiditis which developed into hypoparathyroidism and hypothyroidism.

\section{Case report}

The patient was a 36 year old woman without familial background of thyroid pathology and who did not originate from a geographical area of endemic goitre. She had not undergone craniocervical radiation. Nine months before being sent to our hospital, she began to suffer asthenia, somnolence, constipation, weight gain and dryness of skin. Two months later, she noted a painless lump on the front of her neck which led her to seek medical attention. It was discovered that she had intense hypothyroidism with a thyroxine $\left(\mathrm{T}_{4}\right)$ level of $15.87 \mathrm{nmol} / \mathrm{l}$ and thyroid stimulating hormone (TSH) of $110 \mathrm{mU} / \mathrm{l}$. Echography defined her disorder as diffuse goitre which, in the scintigraphic study, showed no radioisotopic uptake. Her erythrocyte sedimentation rate was $56 \mathrm{~mm}$ in the first hour. Antithyroglobulin antibodies were negative and antimicrosomal antibodies positive at a ratio of $1: 25,000$. The remainder of the analytical study, including blood calcium, was normal. With the diagnosis of hypothyroidism due to Hashimoto's thyroiditis, she

Correspondence: F. Marín Díez, M.D.

Accepted: 13 December 1988 was treated with thyroxine, resulting in the diminution of her goitre and clinical improvement.

One month before coming to our hospital, she began to experience dysphagia with solids and liquids, dysphonia, nocturnal stridor, anorexia and weight loss of $5 \mathrm{~kg}$. She felt a sharp pain in the thyroid area which radiated to both ears.

Examination revealed an asthenic individual with hoarseness of voice. Her thyroid gland was 3 times its normal size, of strong hard consistency, and firmly adherent to the adjacent tissue planes. It was not painful and palpation indicated the absence of adenopathy. The remainder of the physical examination was normal.

Under treatment with $100 \mu \mathrm{g} /$ day of thyroxine, she presented a serum $T_{4}$ of $79.8 \mathrm{nmol} / 1$ (normal range: $51.4-154.4 \mathrm{nmol} / \mathrm{l})$, triiodothyronine $\left(\mathrm{T}_{3}\right)$ of $1.1 \mathrm{nmol} / 1$ (normal range: $1.54-3.08 \mathrm{nmol} / \mathrm{l}$ ), TSH of $18.38 \mathrm{mU} / 1$ (normal range: $0.2-5 \mathrm{mU} / \mathrm{l}$ ) and a $\mathrm{T}_{3}$ resin uptake of $24.50 \%$ (normal range: $25-35 \%$ ). Antithyroglobulin antibodies were negative and antimicrosomal antibodies were positive at a titre of $1: 6,400$. There was no uptake of the radioisotope by the thyroid and echography revealed a diffuse hyperplasia with multiple, poorly defined, solid nodules distributed throughout the gland. Radiography of thorax showed tracheal stenosis.

Blood calcium, calculated as the mean of three determinations, was $1.85 \mathrm{mmol} / \mathrm{l}$ (normal range: $2.17-2.67 \mathrm{mmol} / \mathrm{l}$ ) and blood phosphorus was $1.56 \mathrm{mmol} / 1$ (normal range: $0.95-1.71 \mathrm{mmol} / \mathrm{l}$ ). Serum proteins, haemogram, creatinine, electrolytes, lipids, liver function and coagulation were all normal. Her parathyroid hormone (C-terminal PTH) level, as determined by commercial kit (Immune Nuclear Corp., Minnesota), was $0.58 \mu \mathrm{g} / \mathrm{l}$ (normal:

(C) The Fellowship of Postgraduate Medicine, 1989 
$0.66 \pm 0.33 \mu \mathrm{g} / \mathrm{l})$. There was no clinical alteration derived from hypocalcaemia, nor was there sign of intestinal malabsorption. Fine-needle punctureaspiration was performed, affording abundant follicular elements and Hürthle cells, which resulted in a cytological diagnosis of follicular neoplasia.

It was decided to operate, and during surgery it was observed that the thyroid gland had been replaced by a fibrous mass of stony hard consistency which infiltrated the neighbouring muscles. Simple isthmectomy was performed to remove $7 \mathrm{~g}$ of tissue, but without manipulation of the remainder. Histologically, the specimen was intensely collagenized fibrous tissue with focal areas of lymphocytic infiltration (Figure 1). No thyroid or parathyroid tissue was observed. After surgery, the patient's local compressive symptoms improved. Serum calcium (mean of three determinations) was $1.77 \mathrm{mmol} / \mathrm{l}$; phosphorus, $1.56 \mathrm{mmol} / \mathrm{l}$; and PTH, $0.40 \mu \mathrm{g} / \mathrm{l}$. She was treated with thyroxine and vitamin $\mathrm{D}_{3}$ to maintain normal blood calcium and thyroid hormone levels within satisfactory limits. Eighteen months postsurgery, she remains asymptomatic except for a progressive increase in her hoarseness. Laryngological examination has revealed bilateral recurrent paralysis.

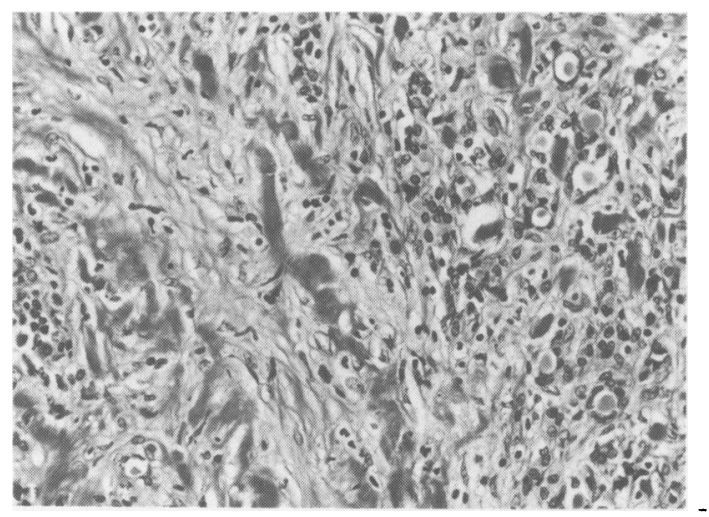

Figure 1 Riedel's thyroiditis. The normal thyroid tissue is largely replaced by a densely collagenized connective with some chronic inflammatory infiltrate. Observe some residual thyroid follicles, $\times 225$.

\section{Discussion}

The appearance of hypoparathyroidism in Riedel's thyroiditis is a rare occurrence. We have found only one well-documented case and reference to another possible instance in the literature. ${ }^{3}$ In our patient, as in the two aforementioned cases, there were no clinical $\frac{2}{<}$ manifestations secondary to hypocalcaemia, probably $\mathbb{\infty}$ because the involvement of the parathyroid glands $c$ was produced by slow but progressive infiltration by fibrous tissue. The clinical and complementary data $\stackrel{0}{+}$ permit us to reasonably rule out other pathologicalo entities which would justify the presence of hypocal- 흘 caemia together with normal PTH levels.

Hypothyroidism is not a usual manifestation of $\stackrel{\mathbb{Q}}{\varnothing}$ Riedel's thyroiditis either. Woolner et al. ${ }^{4}$ found $\$$ 5 myxoedematous patients in a series of 20 cases of ${ }^{\circ}$ Riedel's thyroiditis. In all of them there was an almost ${ }^{\circ}$ total destruction of the thyroid gland, which is the $\overrightarrow{\vec{\omega}}$ mechanism invoked to explain the thyroid hypofunc- o tion. In spite of the fact that antimicrosomalo antibodies were detected in our patient, the levels did 3 not reach those characteristic of Hashimoto's or thyroiditis. Moreover, the marked infiltration of the adjacent tissue confirmed during surgery and the $\stackrel{\curvearrowright}{\perp}$ histological study rules out lymphomatous thyroiditis. $\dot{\omega}_{\infty}$ In this regard, it is of interest to point out that in the $\stackrel{\infty}{\overrightarrow{0}}$ initial descriptions of Riedel's thyroiditis, it was $\frac{}{5}$ suggested that it might be considered a final stage of Hashimoto's thyroiditis. ${ }^{5}$ Presently, however, the two $\subseteq$ are generally considered to be nosologically different $\overparen{\Phi}$ disorders. $^{6}$

To distinguish between Riedel's thyroiditis anf undifferentiated thyroid carcinomas is an importam aspect of the diagnostic assessment of this disease Clinically, it is impossible to make an absolutery certain diagnosis. In our case, fine-needle puncture-

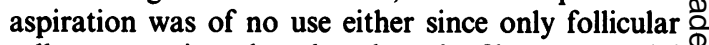
cells were aspirated, rather than the fibrous material $\stackrel{\AA}{2}$ characteristic of this type of thyroiditis. It has even $\overrightarrow{\overrightarrow{0}}$ been observed that, on occasion, biopsy itself may be 3 insufficient as there are cases of undifferentiated carcinomas with a significant amount of fibrous component. ${ }^{7}$ The clinical evolution of our patient after $\overline{0}$ more than two years of survival allows us to rule out 3 the existence of undifferentiated carcinoma.

With respect to treatment, isthmectomy is the technique of choice and its application improved the compressive picture of our patient. The control of the thyroxine and PTH deficiencies by routine means was 윽 satisfactory. Nevertheless, the patient presents pro- $D$ gressive paralysis of the vocal cords, presumably secondary to fibrosis of the recurrent nerves, which N demonstrates the occasionally aggressive character of this disorder. 


\section{References}

1. Levine, S.N. Current concepts of thyroiditis. Arch Intern Med 1983, 143: 1952-1956.

2. Hay, I.D. Thyroiditis: a clinical update. Mayo Clin Proc 1985, 60: 836-843.

3. Chopra, D., Wool, M., Crosson, A. \& Sawin, C.T. Riedel's struma associated with subacute thyroiditis, hypothyroidism, and hypoparathyroidism. J Clin Endocrinol Metab 1978, 46: 869-871.

4. Woolner, L.B., McConahey, W.M. \& Beahrs, O.H. Invasive fibrous thyroiditis (Riedel's struma). $J$ Clin Endocrinol Metab 1957, 17: 201-220.
5. Graham, A. Riedel's struma in contrast to struma lymphomatosa (Hashimoto). West J Surg 1931, 39: 681-689.

6. Oertel, J.E. \& LiVolsi, V.A. Pathology of thyroid diseases. In: Ingbar, S.H. \& Braverman, L.E. (eds) Werner's The Thyroid. J.B. Lippincott, Philadelphia, 1986, pp. $658-659$.

7. Hamburger, J.I. The various presentations of thyroiditis. Diagnostic considerations. Ann Intern Med 1986, 104: 219-224. 